\title{
Local Therapy of Early Breast Cancer*
}

\author{
Florian Fitzal $^{\mathrm{a}}$ Otto Riedl ${ }^{\mathrm{b}}$ Raimund Jakesz ${ }^{\mathrm{a}}$ \\ a University Vienna Medical School, Department of Surgery, Vienna, \\ ${ }^{b}$ LKH Krems, Department of Surgery Krems, Austria
}

\section{Key Words}

Breast cancer, local therapy - Ductal carcinoma in situ .

Sentinel node biopsy - Oncoplastic surgery .

Radiotherapy, postmastectomy · Partial breast

irradiation

\section{Summary}

This review discusses the 2007 St. Gallen oral presentations and posters on the subject of local treatment of primary breast cancer. With a view to surgical interventions, recent results are examined in the management of ductal carcinoma in situ and advanced disease, in sentinel node biopsy and in oncoplastic surgery. In terms of radiotherapy, the focus of this report is on postmastectomy and partial breast irradiation, radiotherapy and systemic therapy, and quality-of-life questions. Finally, conclusions are given with respect to novel developments and unresolved research issues in local therapies as reflected at this year's St. Gallen Breast Cancer Conference.

\section{Introduction}

Local therapy can be divided into surgery and radiotherapy. At this year's St. Gallen breast cancer conference, 3 hours of oral presentations and 30 posters were presented on the field of local therapy, accounting for $33 \%$ of the total conference

*Presentations at the 10th International Conference on 'Primary Therapy of Early Breast Cancer', St. Gallen, Switzerland, 2007

\author{
Schlüsselwörter \\ Mammakarzinom, Lokaltherapie - Duktales Carcinoma in \\ situ - Sentinel-Node-Biopsie - Onkoplastische Chirurgie · \\ Radiotherapie nach Mastektomie - Partielle \\ Brustbestrahlung
}

\section{Zusammenfassung}

In der folgenden Übersicht werden die im Zusammenhang mit der lokalen Therapie des primären Mammakarzinoms stehenden Präsentationen und Poster von St. Gallen 2007 besprochen. Im Hinblick auf operative Interventionen werden jüngste Ergebnisse in der Behandlung des duktalen Carcinomas in situ und fortgeschrittener Erkrankung sowie auch in der Sentinel-Node-Biopsy und der onkoplastischen Chirurgie abgehandelt. Im Bereich der Strahlentherapie liegt der Schwerpunkt dieses Berichts auf der Radiotherapie nach Mastektomie und der partiellen Brustbestrahlung, Radiotherapie und systemischen Therapie sowie der Lebensqualität. Schließlich werden Schlussfolgerungen im Hinblick auf neueste Entwicklungen und noch offene Forschungsinhalte im Spiegel der diesjährigen St. Gallener Konferenz gezogen.

time. Comparing the number of prospective studies for local therapy with systemic therapy, this percentage of total conference time devoted to local therapy issues seems to be very high at first sight. However, if we include the satellite symposiums in this calculation, the local therapy proportion decreases to $14 \%$. Moreover, only 8 questions concerning local therapy, all dedicated to radiotherapy, were raised at the panel discussion session. The Panel's heterogeneous answers to these questions demonstrated that there is still a lot of work to do. Questions concerning surgical issues were not addressed apart from stimulating and exciting overview lectures which in fact

\begin{tabular}{|c|c|}
\hline KARGER & (C) 2007 S. Karger GmbH, Freiburg \\
\hline $\begin{array}{l}\text { Fax +49 } 7614520714 \\
\text { E-mail Information@Karger.de } \\
\text { www.karger.com }\end{array}$ & $\begin{array}{l}\text { Accessible online at: } \\
\text { www.karger.com/brc }\end{array}$ \\
\hline
\end{tabular}

a.o. Univ. Prof. Dr. Florian Fitza 
demonstrated that several issues have not been solved. This paper aims to give a review of the local therapy lectures and posters at the 2007 St. Gallen breast cancer conference.

\section{Surgery}

\section{Ductal Carcinoma in Situ (DCIS)}

Monica Morrow pointed out that there is still a dilemma concerning the unclear pathophysiology of ductal carcinoma in situ (DCIS). The selection of appropriate therapy for an individual is still disputed and ranges from excision, excision and radiotherapy, to mastectomy with or without adjuvant tamoxifen. The role of the sentinel node is not clear either. There is a lack of predictive markers for the risk of invasive or recurrent disease to avoid overtreatment, as patients with DCIS have a risk of death below $5 \%$ regardless of the local therapy applied.

Clarity has been added to the debate of radiotherapy after 3 prospective randomised trials - National Surgical Adjuvant Breast and Bowel Project (NSABP) B17, European Organisation for Research and Treatment of Cancer (EORTC) 10853, UK trial - have been published, demonstrating that the addition of radiotherapy to lumpectomy with negative margins reduces the risk of local recurrence by approximately $50 \%$, independent of any known risk factors such as nuclear grade, young age, growth pattern or margin status [1-3]. An attempt to prospectively explore the hypothesis of Silverstein [4] that margins above $1 \mathrm{~cm}$ may be treated without radiotherapy failed to validate this concept [5] as the local recurrence rate was $2.4 \%$ per year, subsequently leading to a closure of this study after 158 out of 200 planned patients had been randomised. The role of tamoxifen in this respect has not been explored, and this agent may replace radiotherapy after lumpectomy with margins wider than $1 \mathrm{~cm}$. This issue still has to be tested in prospective randomised trials. Positive margins after lumpectomy significantly improve local recurrence-free survival independent of adjuvant treatment. Prospective trials showed that breast-conserving therapy (BCT) followed by radiotherapy and tamoxifen are to be seen as standard treatments for hormone-responsive DCIS (NSABP-B24, International Breast Cancer Intervention Study, IBIS, I) [2, 6. 7]. In the presence of multicentric DCIS or impossibility to reasonably achieve resection-free margins, mastectomy should be performed leading to a BCT rate of $69 \%$ based on the Surveillance Epidemiology and End Results (SEER) data published in 2005. The role of the sentinel node has not been highlighted; however, a palpable mass and sizes larger than $6 \mathrm{~cm}$ imply a higher risk of invasion [8]. Thus, in this patient cohort, a sentinel node biopsy (SNB) may be a good option to avoid a second operation.

Monica Morrow summarised that there is a need for better biological markers to identify DCIS lesions at high risk of de- veloping invasive breast cancer or local recurrence and to tailor local therapy. Overall survival was argued not to be a good endpoint for clinical trials and decision-making processes. Medical treatment has been conducted based on patients' wishes and their physicians' recommendations and was guided by the fear of local recurrence and side effects.

\section{The Sentinel Node}

\section{The Sentinel Node in the Elderly}

The American Society of Clinical Oncology (ASCO) 2005 guidelines recommend SNB in early-stage breast cancer for all patients [9]. John Forbes discussed the use of the SNB technique in the elderly. There is no clear definition of age limit; however, 65 years seems to be the most common cut-off point [10]. Axillary staging in early breast cancer has several implications which may not apply to the elderly as chemotherapy may be contraindicated due to higher co-morbidity risks. Avoidance of morbidity and impairment of quality of life may be more important for elderly women than small absolute improvements in disease-free or overall survival. This may be especially true as early breast cancer in the elderly is usually of smaller size, less aggressive and hormone-responsive. The use of SNB in patients $>70$ years of age demonstrated no significant difference compared with patients $<70$ years of age, with a local recurrence rate of $2.1 \%$ [11] suggesting that SNB is safe in older patients. The International Breast Cancer Study Group (IBCSG) 10-93 trial investigated whether axillary surgery is necessary in older women ( $>60$ years of age) after BCT for early-stage breast cancer [12]. There was no statistically significant difference in disease-free and overall survival comparing both groups; yet arm morbidity was improved in the first 6-12 months after surgery without axillary staging. Thus, axillary staging may be avoided in the elderly with a low risk of lymph node involvement. However, what does low risk mean? NASBP B32 demonstrated that lymphovascular invasion increases the risk of lymph node involvement in 70-yearold patients with $\mathrm{T} 1$ or $\mathrm{T} 2$ breast cancer from 10 to $45 \%$ [13]. Thus, early-stage breast cancer patients without lymphovascular invasion and $>70$ years of age may be spared axillary staging. This, however, has to be tested in prospective randomised trials. Beside these facts, there is also little evidence that complete avoidance of axillary staging in the elderly may be of any benefit, and physicians should be warned not to undertreat the elderly as life expectancy is increasing, with $12 \%$ of the population being $>65$ years of age and $30 \%$ of breast cancer patients being in that age cohort [10].

\section{Controversies in the Use of Sentinel Node Biopsy}

Paolo Veronesi summarised the experience of the Milano European Institute of Oncology (EIO) regarding SNB. Since their 2 prospective randomised trials with 887 patients were completed, the EIO has routinely used SNB in more than 
11,000 patients over the 2000-2006 period. However, there are several subgroups in which routine use of SNB may still be disputed.

Microinvasive breast cancer (pTmic) shows an invasive component and metastatic potential [14]. 11\% of pTmic are associated with positive lymph nodes. Patients with microinvasive disease may be treated with chemotherapy at the EIO, SNB being indicated in pTmic breast cancer at that institution. In this connection, Galimberti et al. presented an ongoing EIO trial as a poster (P64), showing that $11 \%$ of patients with SNB had micrometastases. Patient accrual totals to 389 , and results will be available within the next years.

SNB after prior breast surgery was addressed by Wong et al. [15], indicating that accuracy and false negative rates were similar when comparing 2,206 patients with either preoperative core needle or excision biopsy prior to definitive surgery with SNB. Likewise, work published by Luini et al. [16] showed an identification rate of $99 \%$ with a recurrence rate of $0.7 \%$ after 2 years of follow-up in 543 patients with excisional biopsy prior to SNB. Veronesi suggested that SNB after prior breast surgery is feasible. The feasibility of secondary SNB following SNB has been tested retrospectively by the EIO. Between 2000 and 2006, 202 patients developed an ipsilateral breast cancer recurrence after BCT and SNB. 65 patients were offered a second SNB without axillary dissection in the case of negative SNB. The identification rate was $96 \%$ with $11 \%$ of positive sentinel nodes requiring axillary dissection. No local recurrences were detected after a median follow-up of 45 months [17].

Several studies and 1 multivariate analysis [18] addressed the use of SNB after neoadjuvant chemotherapy. Overall, these 21 studies showed a $91 \%$ identification rate and a $12 \%$ false negative rate. Veronesi concluded that it may be safe to perform SNB after neoadjuvant chemotherapy. Kinoshita et al. presented a poster (P69) dealing with SNB with subsequent level I and II axillary dissection in 104 patients and found an identification rate of $93 \%$, accuracy of $96 \%$ and a false negative rate of $10 \%$. This group also concluded that the SNB after neoadjuvant therapy may be eligible.

In conclusion, Veronesi stated that SNB is a functional rather than an anatomical concept and the only contraindication is a positive axilla prior to surgery. To better evaluate axillary lymph node involvement after neoadjuvant chemotherapy, the EIO applies the positron emission tomography (PET) scan. However, as identification rates should not exceed 10\% [9] and several studies demonstrated false negative rates far beyond $10 \%$ in patients with neoadjuvant therapy, we believe that this indication for SNB needs to be strongly disputed.

\section{Advanced Breast Cancer}

The presence of metastatic breast cancer (stage IV) has long been considered a solid contraindication to ablative surgery for primary breast cancer. The only indication for surgery of the primary cancer was salvage due to bleeding, necrosis or infection. Today, with the ability to earlier detect metastatic disease, we are able to prolong survival due to better palliative systemic therapy. Thus, as our understanding of tumour biology and pathogenesis has also changed, there may be an indication for eradication of the primary tumour in metastatic disease. In this respect, 5 retrospective studies have given evidence that resection of the primary tumour may increase overall survival [19-23]. However, all of these trials show that both groups are very inhomogeneous and include synchronously as well as metachronously metastasized patients. Thus, only a prospective randomised trial may give a clear answer to this question.

In spite of this level III evidence, there is no evidence whatsoever that metastases are beyond the control of the primary tumour and resection of the primary may nullify this control followed by apoptosis of metastases. In fact, the kinetic of metastases increases after primary tumour resection [24] which may be avoided by preoperative chemotherapy [25] in an experimental setting. Thus, we believe that primary chemotherapy to reduce kinetic induction should precede surgical resection of the primary tumour in metastasized breast cancer patients in such prospective randomised trials. Wood argued that metastasized patients have already been treated with surgery, but this has been obscured by classifying the metastasis as $\mathrm{N}$ instead of M. In this regard, the role of surgery to the axilla and the metastases has also to be discussed in prospective trials.

\section{Oncoplastic Surgery}

Only 3 poster presentations dealt with oncoplastic surgery which is one of the main future developments to ameliorate surgery of the breast and patients' quality of life. In this respect, Fitzal et al. presented a poster (P76) on the use of different oncoplastic techniques to improve central lumpectomy defects with a one-stage operation. Results of our group's modified use of the Hall-Findlay technique for breast cancer surgery has been published [26]. Other techniques include the 'batwing' technique and a simple purse-string technique. A Yshape incision was proposed by Szynglarewicz for better cosmesis after mastectomy (P78), and the feasibility of nipplesparing mastectomy with immediate reconstruction was shown in 110 patients by Son et al. (P80) without oncological or cosmetic outcome measurements.

\section{Radiotherapy}

\section{Postmastectomy Radiotherapy}

Results of the Early Breast Cancer Trialists' Collaborative Group (EBCTCG) [27, 28] have demonstrated increased 
postmastectomy radiation in patients with $\mathrm{N} 1$ (1-3 nodes positive) including risk factors such as lymphatic vessel invasion, young age and G3 as well as close margins. This was clearly presented by Harris at the local therapy session. In this regard, Harris showed updated data from 2005 and emphasized that a $10 \%$ absolute improvement in local recurrence-free survival due to additional radiotherapy significantly improved breast cancer-specific and overall survival. For every 4th local recurrence avoided at 5 years, there was 1 additional 15-year survivor. However, a recent report by Mamounas et al. presented at the 2006 San Antonio Breast Cancer Symposium (SABCS), showed that systemic therapy should be added to radiotherapy after mastectomy in node-positive patients in an attempt to improve survival. Today, being reduced with novel methods, side effects are another important aspect of radiotherapy. Overview subset analyses show a clear relationship between irradiation dose to the heart and cardiac deaths.

Harris concluded that patients with 4 positive lymph nodes should receive postmastectomy radiotherapy, while patients with 1-3 affected nodes should present with another risk factor in order to be eligible for radiotherapy. These risk factors may include the node collection ratio, lymphovascular invasion [29], tumour grade and size, and young age. This suggestion was supported by the poster of Mladenovic et al. (P86), showing, in a retrospective analysis of 482 patients, that the addition of radiotherapy to mastectomy in patients with 1-3 positive nodes failed to improve oncological outcomes. In this connection, an ongoing study (BIG 2-04 or MRC/EORTC SUPREMO) is investigating the role of chest wall radiation after mastectomy in breast cancer patients with 1-3 involved nodes and an additional risk factor (grade 3 or lymphovascular invasion) (P88).

\section{Partial Breast Irradiation}

Local relapse occurs at the former tumour site in about $80 \%$ of patients. This has led to the hypothesis that partial tumour bed irradiation may be similar to whole breast irradiation. This reduces the radiation field and may therefore decrease side effects. Partial breast irradiation (PBI) may also overcome the problem of timing with systemic therapy. These possible advantages should be balanced with a possibly worse local recurrence rate and the cosmetic outcome. Different techniques have been used, including electron intra-operative radiotherapy (ELIOT), targeted intra-operative radiotherapy (TARGIT) and MammoSite. The first prospective evaluated 8-year results have been published by Ribeiro et al. [30] from Christies Hospital, demonstrating that partial breast irradiation in $\mathrm{pT} 2 \mathrm{pN} 0 \mathrm{R} 0$ patients increased the local recurrence rate from 10 to $20 \%$. 4 European trials initiating partial breast irradiation before 1990 showed an annual local recurrence rate of up to $10 \%$, while more recent series have demonstrated an annual local recurrence rate below $1 \%$ [31]. The
Salzburg trial showed improved local recurrence rates in partial breast-irradiated patients compared with whole breast-irradiated patients [32]. Patients in the trials differed in terms of grading, tumour size and age, which may have contributed to the better results in the later trials. Thus, there may be certain patients who do worse with partial breast irradiation. Such patients should be excluded while others should be offered this form of radiation treatment. However, more prospective studies are necessary. Thus, partial breast irradiation should not yet be considered standard treatment outside clinical trials for patients with breast cancer. The unresolved questions include the following: which patient should be treated in which treatment protocol, which volume should be treated, and which schedule should be followed?

\section{Radiotherapy and Systemic Therapy}

Harry Bartelink presented this topic raising several important questions. First, he demonstrated that improving local control may improve overall survival, as shown in the latest EBCTCG overview. Second, this overview also suggests that there is only limited, if any, evidence suggesting that systemic therapy may replace radiotherapy. Concerning sequential timing, there has been no significant difference comparing radiotherapy or chemotherapy first in prospective trials for any event [33-36]. However, local recurrence-free survival seems to be increased if radiotherapy is delayed 8 weeks after surgery, as shown in a more recent systemic review [37]. Regarding side effects, there seems to be no evidence that trastuzumab increases the cardiac toxicity of radiotherapy [38], while chemotherapy with cyclophosphamide, methotrexate and fluorouracil (CMF) does [39].

\section{Radiotherapy and Quality of Life}

Prescott et al. presented a poster (P82) demonstrating that quality of life is not significantly different between patients with and without radiotherapy in the Postoperative Radiotherapy in Medium-risk Elderly (PRIME) trial. The EORTC C30 and BR23 indices, together with the EuroQol and the Hospital Anxiety and Depression Scale (HADS), have been applied in this trial.

\section{Conclusion}

The St. Gallen 2007 lectures and posters on local therapy delivered a wide range of both novel developments and unresolved research issues in breast cancer surgery and radiotherapy. As for surgical interventions, we are still clearly in need of better biological markers to identify DCIS lesions at high risk of developing invasive disease or local recurrence and to tailor 
local therapy. SNB is to be considered a functional rather than an anatomical concept, the only contraindication being a positive axilla presurgery. In metastasised patients, primary chemotherapy should precede surgical resection of the primary tumour in an attempt to reduce kinetic induction. Less attention was given this year to oncoplastic surgery which still remains one of the key concepts for future improvements in breast surgery and patients' quality of life. As for recent developments in radiotherapy, an interesting trial is currently investigating the value of chest wall irradiation after mastectomy in women with 1-3 involved nodes plus 1 additional risk factor. Finally, partial breast irradiation cannot yet be considered standard treatment outside clinical trials for patients with breast cancer.

\section{References}

1 Bijker N, Meijnen P, Peterse JL, Bogaerts J, van Hoorebeeck I, Julien JP, Gennaro M, Rouanet P, Avril A, Fentiman IS, Bartelink H, Rutgers EJ Breast-conserving treatment with or without radiotherapy in ductal carcinoma-in-situ: ten-year results of European Organisation for Research and Treatment of Cancer randomized phase III trial 10853a study by the EORTC Breast Cancer Cooperative Group and EORTC Radiotherapy Group. J Clin Oncol 2006;24:3381-3387.

2 Fisher B, Land S, Mamounas E, Dignam J, Fisher ER, Wolmark N: Prevention of invasive breast cancer in women with ductal carcinoma in situ: an update of the national surgical adjuvant breast and bowel project experience. Semin Oncol 2001;28 400-418.

-3 Houghton J, George WD, Cuzick J, Duggan C, Fentiman IS, Spittle M: Radiotherapy and tamoxifen in women with completely excised ductal carcinoma in situ of the breast in the UK, Australia, and New Zealand: randomised controlled trial. Lancet 2003; 362:95-102.

4 Silverstein MJ, Lagios MD, Groshen S, Waisman JR, Lewinsky BS, Martino S, Gamagami P, Colburn WJ: The influence of margin width on local control of ductal carcinoma in situ of the breast. N Engl J Med 1999;340:1455-1461.

$\checkmark 5$ Wong JS, Kaelin CM, Troyan SL, Gadd MA, Gelman R, Lester SC, Schnitt SJ, Sgroi DC, Silver BJ, Harris JR, Smith BL: Prospective study of wide excision alone for ductal carcinoma in situ of the breast. J Clin Oncol 2006;24:1031-1036.

6 Cuzick J, Forbes J, Edwards R, Baum M, Cawthorn S, Coates A, Hamed A, Howell A, Powles T: First results from the International Breast Cancer Intervention Study (IBIS-I): a randomised prevention trial. Lancet 2002;360:817-824.

7 Cuzick J, Forbes JF, Sestak I, Cawthorn S, Hamed $\mathrm{H}$, Holli K, Howell A: Long-term results of tamoxifen prophylaxis for breast cancer - 96-month follow-up of the randomized IBIS-I trial. J Natl Cancer Inst 2007;99:272-282.

$>8$ Goyal A, Douglas-Jones A, Monypenny I, Sweetland $H$, Stevens $G$, Mansel RE: Is there a role of sentinel lymph node biopsy in ductal carcinoma in situ? Analysis of 587 cases. Breast Cancer Res Treat 2006;98:311-314.

-9 Lyman GH, Giuliano AE, Somerfield MR, Benson AB 3rd, Bodurka DC, Burstein HJ, Cochran AJ, Cody HS 3rd, Edge SB, Galper S, Hayman JA, Kim TY, Perkins CL, Podoloff DA, Sivasubramaniam VH, Turner RR, Wahl R, Weaver DL, Wolff AC, Winer EP: American Society of Clinical Oncology guideline recommendations for sentinel lymph node biopsy in early-stage breast cancer. J Clin Oncol 2005;23:7703-7720.
10 Audisio RA, Bozzetti F, Gennari R, Jaklitsch MT, Koperna T, Longo WE, Wiggers T, Zbar AP: The surgical management of elderly cancer patients; recommendations of the SIOG surgical task force. Eur J Cancer 2004;40:926-938.

11 Gennari R, Rotmensz N, Perego E, dos Santos G, Veronesi U: Sentinel node biopsy in elderly breast cancer patients. Surg Oncol 2004;13:193-196.

12 Rudenstam CM, Zahrieh D, Forbes JF, Crivellari D, Holmberg SB, Rey P, Dent D, Campbell I, Bernhard J, Price KN, Castiglione-Gertsch M, Goldhirsch A, Gelber RD, Coates AS: Randomized trial comparing axillary clearance versus no axillary clearance in older patients with breast cancer: first results of International Breast Cancer Study Group Trial 10-93. J Clin Oncol 2006;24:337-344.

13 Julian T, Fourchotte V, Anderson S, Mamounas E, Constantino J, Boudros N, Wolmark N: Predictive factors that identify patients not requiring a sentinel node biopsy: continued analysis of the NSABP-B32 sentinel node trial. SABCS, San Antonio, TX, 2006.

14 Colleoni M, Rotmensz N, Peruzzotti G, Maisonneuve P, Viale G, Renne G, Casadio C, Veronesi P, Intra M, Torrisi R, Goldhirsch A: Minimal and small size invasive breast cancer with no axillary lymph node involvement: the need for tailored adjuvant therapies. Ann Oncol 2004;15:1633-1639.

15 Wong SL, Edwards MJ, Chao C, Tuttle TM, Noyes RD, Carlson DJ, Laidley AL, McGlothin TQ, Ley PB, Brown CM, Glaser RL, Pennington RE, Turk PS, Simpson D, McMasters KM: The effect of prior breast biopsy method and concurrent definitive breast procedure on success and accuracy of sentinel lymph node biopsy. Ann Surg Oncol 2002;9: 272-277.

16 Luini A, Galimberti V, Gatti G, Arnone P, Vento AR, Trifiro G, Viale G, Rotmensz N, Fernandez JR, Gilardi D, Paganelli G: The sentinel node biopsy after previous breast surgery: preliminary results on 543 patients treated at the European Institute of Oncology. Breast Cancer Res Treat 2005;89: 159-163.

17 Veronesi P, Rodriguez-Fernandez J, Garcia-Etienne $\mathrm{C}$, Intra M: Controversies in the use of sentinel nodes: Microinvasion, post-surgery and after preoperative systemic treatment. Breast 2007;16 (suppl 1):S6.

18 Xing Y, Foy M, Cox DD, Kuerer HM, Hunt KK, Cormier JN: Meta-analysis of sentinel lymph node biopsy after preoperative chemotherapy in patients with breast cancer. Br J Surg 2006;93:539-546.

19 Babiera GV, Rao R, Feng L, Meric-Bernstam F, Kuerer HM, Singletary SE, Hunt KK, Ross MI, Gwyn KM, Feig BW, Ames FC, Hortobagyi GN: Effect of primary tumor extirpation in breast cancer patients who present with stage IV disease and an intact primary tumor. Ann Surg Oncol 2006;13: 776-782.
20 Blanchard DK, Bhatia P, Hilsenbeck SG, Elledge RM: Does surgical management of stage IV breast cancer effect outcome? SABCS, San Antonio, TX, 2006.

21 Carmichael AR, Anderson ED, Chetty U, Dixon JM: Does local surgery have a role in the management of stage IV breast cancer? Eur J Surg Oncol 2003;29:17-19.

22 Khan SA, Stewart AK, Morrow M: Does aggressive local therapy improve survival in metastatic breast cancer? Surgery 2002;132:620-626; discussion 626-627.

23 Rapiti E, Fioretta G, Verkooijen HM, Vlastos G, Schafer P, Sappino AP, Kurtz J, Neyroud-Caspar I, Bouchardy C: Survival of young and older breast cancer patients in Geneva from 1990 to 2001. Eur J Cancer 2005;41:1446-1452.

24 Fisher B, Gunduz N, Coyle J, Rudock C, Saffer E: Presence of a growth-stimulating factor in serum following primary tumor removal in mice. Cancer Res 1989;49:1996-2001.

-25 Fisher B, Saffer E, Gunduz N, Coyle J, Rudock C: Serum growth factor following primary tumor removal and the inhibition of its production by preoperative therapy. Prog Clin Biol Res 1990;354A: 47-60.

26 Fitzal F, Nehrer G, Hoch D, Riedl O, Gutharc S, Deutinger M, Jakesz R, Gnant M: An oncoplastic procedure for medio-cranial and central breast cancer. Eur J Surg Oncol 2007;submitted.

27 EBCTCG: Effects of radiotherapy and of differences in the extent of surgery for early breast cancer on local recurrence and 15-year survival: an overview of the randomised trials. Lancet 2005;366: 2087-2106.

28 EBCTCG: Radiotherapy for early breast cancer. Cochrane Database Syst Rev 2002:CD003647.

29 Schoppmann SF, Bayer G, Aumayr K, Taucher S, Geleff S, Rudas M, Kubista E, Hausmaninger H, Samonigg H, Gnant M, Jakesz R, Horvat R: Prognostic value of lymphangiogenesis and lymphovascular invasion in invasive breast cancer. Ann Surg 2004;240:306-312.

30 Ribeiro GG, Magee B, Swindell R, Harris M, Banerjee SS: The Christie Hospital breast conservation trial: an update at 8 years from inception. Clin Oncol (R Coll Radiol) 1993;5:278-283.

31 Zannis V, Beitsch P, Vicini F, Quiet C, Keleher A, Garcia D, Snider H, Gittleman M, Kuerer H, Whitacre E, Whitworth P, Fine R, Haffty B, Stolier A, Mabie J: Descriptions and outcomes of insertion techniques of a breast brachytherapy balloon catheter in 1403 patients enrolled in the American Society of Breast Surgeons MammoSite breast brachytherapy registry trial. Am J Surg 2005;190: 530-538. 
>32 Reitsamer R, Sedlmayer F, Kopp M, Kametriser G, Menzel C, Deutschmann H, Nairz O, Hitzl W, Peintinger F: The Salzburg concept of intraoperative radiotherapy for breast cancer: results and considerations. Int J Cancer 2006;118:2882-2887.

33 Recht A: Radiotherapy and surgery in early breast cancer. N Engl J Med 1996;334:989.

>34 Recht A, Come SE, Henderson IC, Gelman RS, Silver B, Hayes DF, Shulman LN, Harris JR: The sequencing of chemotherapy and radiation therapy after conservative surgery for early-stage breast cancer. N Engl J Med 1996;334:1356-1361.

35 Bellon JR, Come SE, Gelman RS, Henderson IC, Shulman LN, Silver BJ, Harris JR, Recht A: Sequencing of chemotherapy and radiation therapy in early-stage breast cancer: updated results of a prospective randomized trial. J Clin Oncol 2005;23: 1934-1940.

-36 Bellon JR, Harris JR: Chemotherapy and radiation therapy for breast cancer: what is the optimal sequence? J Clin Oncol 2005;23:5-7.

- 37 Huang J, Barbera L, Brouwers M, Browman G, Mackillop WJ: Does delay in starting treatment affect the outcomes of radiotherapy? A systematic review. J Clin Oncol 2003;21:555-563.

38 Halyard MY, Pisansky TM, Solin LS, Marks LB, Pierce LJ, Dueck A, Perez EA: Adjuvant radiotherapy (RT) and trastuzumab in stage I-IIA breast cancer: toxicity data from North Central Cancer Treatment Group Phase III trial N9831. J Clin Oncol 2006;24:523.

-39 Hooning MJ, Botma A, Aleman BM, Baaijens MH, Bartelink H, Klijn JG, Taylor CW, van Leeuwen FE: Long-term risk of cardiovascular disease in 10year survivors of breast cancer. J Natl Cancer Inst 2007;99:365-375. 